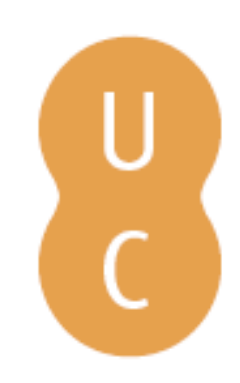

\title{
pompalina
}

\section{Determining a safety condition in the prevention of eruptive fires}

\author{
Autor(es): \\ F.J., Chatelon; J.H., Balbi; J.L., Rossi; A., Simeoni; D.X., Viegas; T., \\ Marcelli
}

Publicado por: Imprensa da Universidade de Coimbra

URL

persistente:

URI:http://hdl.handle.net/10316.2/34302

DOI:

DOI:http://dx.doi.org/10.14195/978-989-26-0884-6_148

Accessed : $\quad$ 26-Apr-2023 16:37:45

A navegação consulta e descarregamento dos títulos inseridos nas Bibliotecas Digitais UC Digitalis, UC Pombalina e UC Impactum, pressupõem a aceitação plena e sem reservas dos Termos e Condições de Uso destas Bibliotecas Digitais, disponíveis em https://digitalis.uc.pt/pt-pt/termos.

Conforme exposto nos referidos Termos e Condições de Uso, o descarregamento de títulos de acesso restrito requer uma licença válida de autorização devendo o utilizador aceder ao(s) documento(s) a partir de um endereço de IP da instituição detentora da supramencionada licença.

Ao utilizador é apenas permitido o descarregamento para uso pessoal, pelo que o emprego do(s) título(s) descarregado(s) para outro fim, designadamente comercial, carece de autorização do respetivo autor ou editor da obra.

Na medida em que todas as obras da UC Digitalis se encontram protegidas pelo Código do Direito de Autor e Direitos Conexos e demais legislação aplicável, toda a cópia, parcial ou total, deste documento, nos casos em que é legalmente admitida, deverá conter ou fazer-se acompanhar por este aviso.

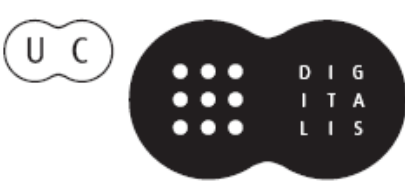




\section{ADVANCES IN}

Forest Fire

\section{RESEARCH}

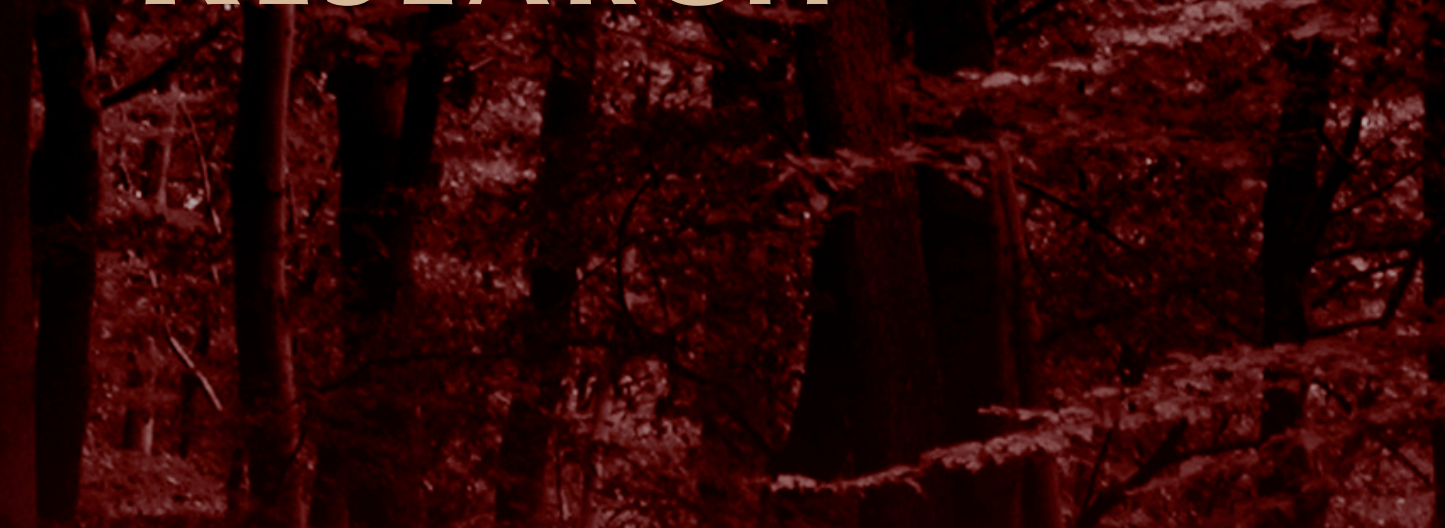

\section{DOMINGOS XAVIER VIEGAS}

\section{EDITOR}




\title{
Determining a safety condition in the prevention of eruptive fires
}

\author{
Chatelon F.J. ${ }^{a}$, Balbi J.H. ${ }^{a}$, Rossi J.L. ${ }^{a}$, Simeoni A. ${ }^{\mathrm{b}}$, Viegas D.X. ${ }^{\mathrm{c}}$, Marcelli T. ${ }^{\mathrm{a}}$ \\ ${ }^{a}$ Università di Corsica, Systèmes Physiques pour l'Environnement, UMR CNRS 6134, Campus \\ Grossetti,20250Corti, chatelon@univ-corse.fr, balbi@univ-corse.fr, rossi@univ-corse.fr, \\ marcelli@univ-corse.fr \\ ${ }^{b}$ Centre for Fire Safety Engineering, Institute for Infrastructure and Environment, University of \\ Edinburgh, A.Simeoni@ed.ac.uk \\ ${ }^{c}$ Centre of Studies on Forest Fires, ADAI, University of Coimbra, Portugal, \\ xavier.viegas@dem.uc.pt
}

\begin{abstract}
Eruptive fires are one of the main causes of human losses in forest fire fighting. This phenomenon is fairly rare, unpredictable and thus extremely dangerous for firefighters (or civilians). Many casualties result from several accidents identified in the last fifty years around the world. Indeed, people involved in fire fighting activities are not prepared for facing such an unpredictable phenomenon. Very few literature is available to support either modelling or occurrence prediction for this phenomenon. Eruptive fire behaviour usually describes an extreme case of dynamic fire behaviour in which a sudden increase of the fire front rate of spread (ROS) in a short lapse of time is observed. So the question of predicting an eruption's occurrence is a crucial point for the fire fighters' safety. In this study, it is assumed that the eruption is due to physical considerations. The mechanism responsible for this erratic behaviour is the pioneering interpretation proposed by Viegas (2005) which consists in a feedback between the ROS and a convective air flow created by the fire itself. A physical modelling for this "induced wind" is given and is coupled with a simplified physical propagation model for surface fires. If the solution of the coupled system usually converges, it may diverge under certain conditions, leading to a fire eruption. It is then possible to obtain a physical condition which gives the impossibility (or not) for a fire to turn into an eruptive fire and the model is able to predict the occurrence of a fire eruption according to the triangle of fire. The model is tested by comparing its numerical results on the one hand to a set of experiments carried out at laboratory scale and on the other hand to an outdoor wildfire (Kornati accident).
\end{abstract}

Keywords: Eruptive fire, fire spread, physical model, prevention, eruption's occurrence

\section{Introduction}

The term 'blowup' used in wildland fires by Butler et al. (1998) indicates a rapid change from a low intensity surface fire to a high fire burning through the whole vegetation complex, from surface to canopy and demonstrates dramatically larger flame heights, higher energy release rates and rates of spread that are faster than usual fires. As this work focuses on the acceleration of surface fires, the designation of fire eruption proposed by Viegas (2005) is used and describes the sudden change in rate of spread of the head fire and in energy release within a very short lapse of time. Viegas and Simeoni (2011) reviewed the mechanisms (physical or chemical considerations, variation of external conditions, etc...) that are described in literature to explain the onset and development of fire eruptions. The major part of these diagnoses are refuted by examples of real fires occurred in the past. Among all these explanations, the pioneering interpretation proposed by Viegas (2005) must be highlighted. Actually, it is based on the coupling of the own properties of the spreading fire with other conditions (wind, topography) and consists in a feedback effect caused by the convective flow induced by the fire in the presence of wind or/and a positive slope. The fire creates an 'induced wind' which transports oxygen to the reaction zone which intensifies the combustion process and consequently flame length and ROS. So the reaction needs more and more ambient air. This feedback process will increase continuously and the ROS could reach very important values if it is not inhibited by some external mechanisms. This strong air flow movement was proved at the laboratory scale by Viegas and Pita 
(2004) and observed at the field scale (Viegas et al. 2002). Moreover, the testimony of the one fire fighter who survives the Kornati fire accident (Stipanicev and Viegas, 2009), the meteorological measures of the wind speed during the freixo accident (Viegas 2005) are clear evidences of the importance and the relevance of the induced wind. Viegas (2005) suggested a mathematical model (constituted by a non linear differential equation) that predicts the fast increasing of the ROS. One can also cite the model developed by Dold et al. (2011) in which the phenomenon is the result of a flow attachment and the ROS is assumed to vary as a power-law of the fireline intensity. If these empirical models can reproduce the fire behaviour during the eruption, they do not predict the eruption's onset and to our knowledge, such a model does not exist.

This work focuses on the existence of a condition for predicting either extreme or usual fire behaviour. A physical modelling of the induced wind is coupled with the simplified physical propagation model for surface fires developed at the University of Corsica (Balbi et al. 2007, 2009, 2010). In some cases, this coupling can diverge, leading to a fire eruption's onset.

\section{Equations of the simplified physical propagation model}

As some authors (e.g. Albini 1985, Telisin 1974, Van Wagner 1967) assumed that radiation was the dominant process in the contribution of heat to unburnt fuel, the propagation model developed at the University of Corsica (Balbi et al. 2007) was only based on radiation. It was elaborated to be as complete as possible with regard to the equations that govern fires, whilst also being computationally cheap. To this end, the use of partial differential equations was avoided because of their associated long calculation times and also because of the difficulty of making a sensitive study of the fire behaviour with respect to the different parameters involved (e.g. environmental, topographic, or fuel bed properties). This model was later improved and successfully confronted to sets of experiments at the laboratory scale with aligned slope and wind and at the field scale (Balbi et al. 2009) or confronted to the set of experiments conducted by Viegas (2004a) where slope and wind are not aligned. The improvements brought by Chatelon et al. (2010) or Marcelli et al. (2011) have changed the propagation model into a complete fire behaviour model in which rate of spread (ROS), flame tilt angle, flame temperature, flame length, radiant fraction and vertical velocity due to buoyancy are given.

The two main algebraic equations of the model are the following:

$$
\begin{gathered}
\tan \gamma=\tan \alpha+\frac{U}{u_{0}} \\
R=R_{b}+R_{f}
\end{gathered}
$$

Equation (1) gives the flame tilt angle $\gamma$ depending on the slope angle $\alpha$, the normal component of the wind velocity $U$ and the upward gas velocity $u_{0}$. Equation (2) provides the ROS $R$ as a function of the two radiative contributions from the flame $\left(R_{f}\right)$ and from the burning fuel bed $\left(R_{b}\right)$. These contributions are obtained by considering the flame and the base of the flame as grey radiant panels:

$$
\begin{gathered}
R_{b}=\frac{e}{\sigma} \frac{B T_{b}{ }^{4}}{C_{p} \Delta T+m \Delta h} \\
R_{f}=A R \frac{1+\sin \gamma-\cos \gamma}{1+\frac{R \cos \gamma}{r_{0}}}
\end{gathered}
$$

where $C_{p}$ denotes the specific heat of the vegetative fuel, $B$ the Stefan-Boltzmann constant, $m$ the fuel moisture content, $\Delta h$ the heat of latent evaporation, $\sigma$ the fuel load, $e$ the fuel bed depth, $T_{b}$ the fuel burning particles temperature and $\Delta T=T_{i}-T_{a}$ the difference between ignition temperature and ambient 
air temperature. The coefficient $r_{0}$ is a ROS factor that can be expressed as a function of the surface area to volume ratio of the fuel elements (Chatelon et al. 2010).

The coefficient $A$ in equation (4) involves flame radiation. It represents the magnitude of the flame radiation related to the ignition energy. Its expression given in equation (5) depends on the heat of combustion of the pyrolysis gases $\Delta H$, a radiant factor $\chi_{0}$, the absorption coefficient $v$ and a corrective term $Y$ to the view factor introduced by Koo et al. (2005) in order to improve Pagni and Peterson's model (Pagni and Peterson 1973). This term $Y$ depends on dynamic fire parameters (ratio between fire front width $W$ and flame length $l$ ).

$$
A=v \frac{\chi_{0} \Delta H}{4\left(c_{p} \Delta T+m \Delta h\right)} Y
$$

This model was successfully used to model several laboratory experiments (e.g. Guijarro et al. 1997, Mendes-Lopes et al. 2003, Viegas 2004b) and applied to some field-scale fires (e.g. McArthur 1969, Cheney and Gould 1995, Fernandes 2001). As this model is a steady-state model, it cannot reproduce a fire eruption which is an unsteady phenomenon (Viegas 2005, Dold and Zinoviev 2009). Thus a submodel which describes the effect of the induced wind defined by Viegas (2005) has to be added.

\section{Induced wind modelling}

Under slope and weak wind conditions, the fire creates an induced airflow $U_{i}$ in order to compensate the draught caused by the hot gases moving upwards. Considering a positive slope, the airflow comes from both sides of the fire front but only the airflow coming from the burned zone enters the flame. Indeed, the flame geometry causes an important deviation of the trajectory of the fresh air stream coming from the unburnt zone. So, the induced wind velocity under the flame is assumed to be practically zero. Consequently, there is no indraft at the fire front. On the other hand, the airflow coming from the burned zone is only slightly deviated, particularly near the ground, as it gets into the flame and supplies the reaction zone with oxygen.

Viegas and Pita (2004) clearly showed the presence of induced wind at the laboratory scale. Their experiments consisted in measuring the fire spread in canyons, using a combustion table with two inclined faces in order to create a canyon geometry. A first set of experiments in opened canyons showed a very fast spreading fire, which can be considered as eruptive. When the induced-wind was inhibited by a plate placed across the base of the canyon, the spread was much slower and the fire never showed an eruptive nature.

At the field scale, the Freixo de Espada-a-Cinta accident reported by Viegas (2004c) is a good example of the presence of an induced wind. Indeed, when the fire reached the base of a canyon, it was given as practically extinguished and the wind was blowing from the northwest in a downslope direction with a velocity on the order of $15 \mathrm{~km} / \mathrm{h}$. Suddenly, the wind turned to south-southwest, which is approximately the upslope direction and rose to $65 \mathrm{~km} / \mathrm{h} 30$ minutes later, with gusts up to $96 \mathrm{~km} / \mathrm{h}$. These data were retrieved by a meteorological station located on top of the ridge that was located in the spreading direction of the fire front. They clearly showed the impact of the induced wind because no other atmospheric phenomenon can explain this eruption.

The induced wind formulation is derived from a simplified mass balance based on the geometrical flame characteristics between the top of the vegetal stratum and the mid-height flame. The equality between inflow and outflow can be written as:

$$
\rho_{a} \frac{H}{2} U_{i}=\rho \frac{L}{2} u \cos \alpha
$$

where $U_{i}$ is the self induced wind, $\rho$ is the combustion gases density, $\rho_{a}$ is the ambient air density, $L$ is the flame depth, $H$ is the flame height and $u$ is the upward gases velocity with slope (see Figure 1). 


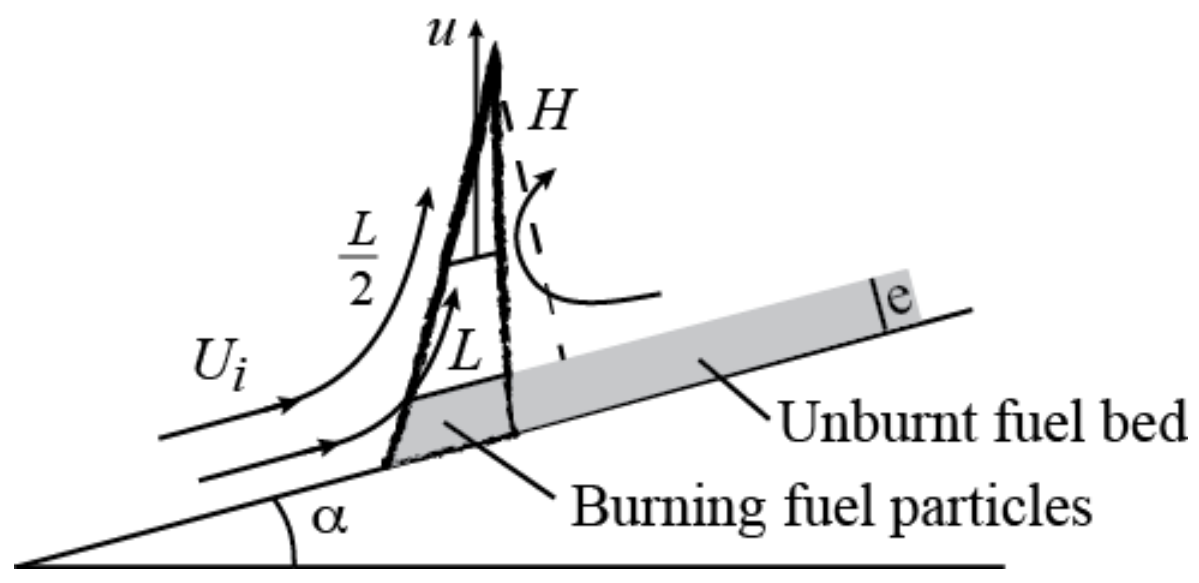

Figure 1. Qualitative description of the flame geometry.

Using the relationship $u=\frac{u_{0}}{\cos \alpha}$ (Balbi et al. 2009), the ratio between induced wind $\left(U_{i}\right)$ and upward gases velocity at mid-height flame $\left(u_{0}\right)$ is

$$
\frac{U_{i}}{u_{0}}=\frac{\rho}{\rho_{a}} \frac{L}{H}=\frac{\rho}{\rho_{a}} \frac{R \tau}{H}=\frac{R}{p}
$$

where $\tau$ is the flame residence time and

$$
p=\frac{T}{T_{a}} \frac{H}{\tau}=2 \frac{\chi_{0} \Delta H \rho_{v} v r_{0}}{B T_{a} T^{3} \tau_{0}}
$$

with the flame height given by Marcelli et al. (2011)

$$
H=\frac{2 \chi_{0} \Delta H \rho_{v} v r_{00}}{B T^{4}}
$$

The flame residence time $\tau$ in equation (8) is expressed by using the relationship provided by Anderson (1969): $\tau=\tau_{0} / s$ with $\tau_{0}=75591 \mathrm{~m}^{-1} \cdot \mathrm{s}$. This time is inversely proportional to the fuel surface area to volume ratio $s$. Notice that this relationship is currently used in BEHAVE (Andrews 1986) in operational conditions. Using equation (7), the relationship (1) is changed in

$$
\tan \gamma=\tan \alpha+\frac{R}{p}
$$

Finally the fire spread behaviour taking into account the self-induced wind, is obtained by solving the following system:

$$
\begin{gathered}
R=p(\tan \gamma-\tan \alpha) \\
R=R_{b}+A R \frac{1+\sin \gamma-\cos \gamma}{1+\frac{R \cos \gamma}{r_{0}}}
\end{gathered}
$$

\section{The safety condition}

In the coordinate system $(\tan \gamma, R)$, the steady solutions of the model are defined as the intersection of the growing function given by equation (12) and the straight line given by equation (11). Chatelon et 
al. (2010) have showed that equation (12) exhibits two different behaviours for the ROS depending on the value of the coefficient $A$. Indeed the ROS $R$ given by equation (12) is always a growing function which presents an horizontal asymptote when $A$ is smaller than $1 / 2$ and an affine asymptote (whose slope denoted by $p_{\infty}$ is equal to $r_{0}(2 A-1)$ ) otherwise (see figure 2 ).
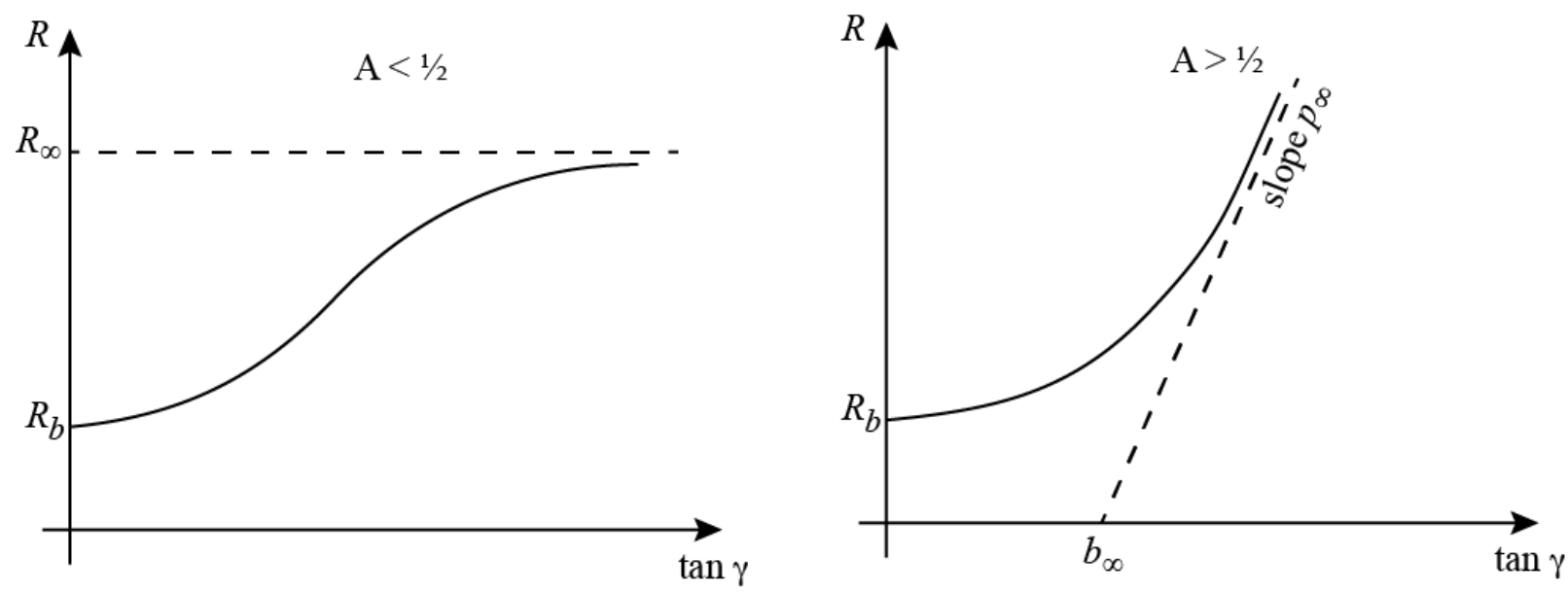

Figure 2. Qualitative illustration of the different rate of spread behaviours as a function of the flame tilt angle according to the value of the coefficient $A$.

A qualitative graphic analysis leads to several different cases, according to the values of the slope angle and the coefficients $A$ and $p$ :

- When $A<1 / 2$, at least one solution of the system (11-12) always exists and is finite due to the horizontal asymptote exhibited by the ROS given by equation (12). So a fire eruption is impossible because the ROS cannot go to infinity. (see left side of figure 3 )

- When $A>1 / 2$, if $p$ is greater than $p_{\infty}$, the intersection of the ROS given respectively by equations (11) and (12) always exists. Its value may be great (when the slope is steep) but is always finite. So the fire never erupts (right side of figure 3 ).

- When $A>1 / 2$, if $p$ is smaller than $p_{\infty}$, a fire eruption is possible but not sure. It depends on the value of the terrain slope angle. When $\alpha$ is greater enough, fire inevitably erupts.
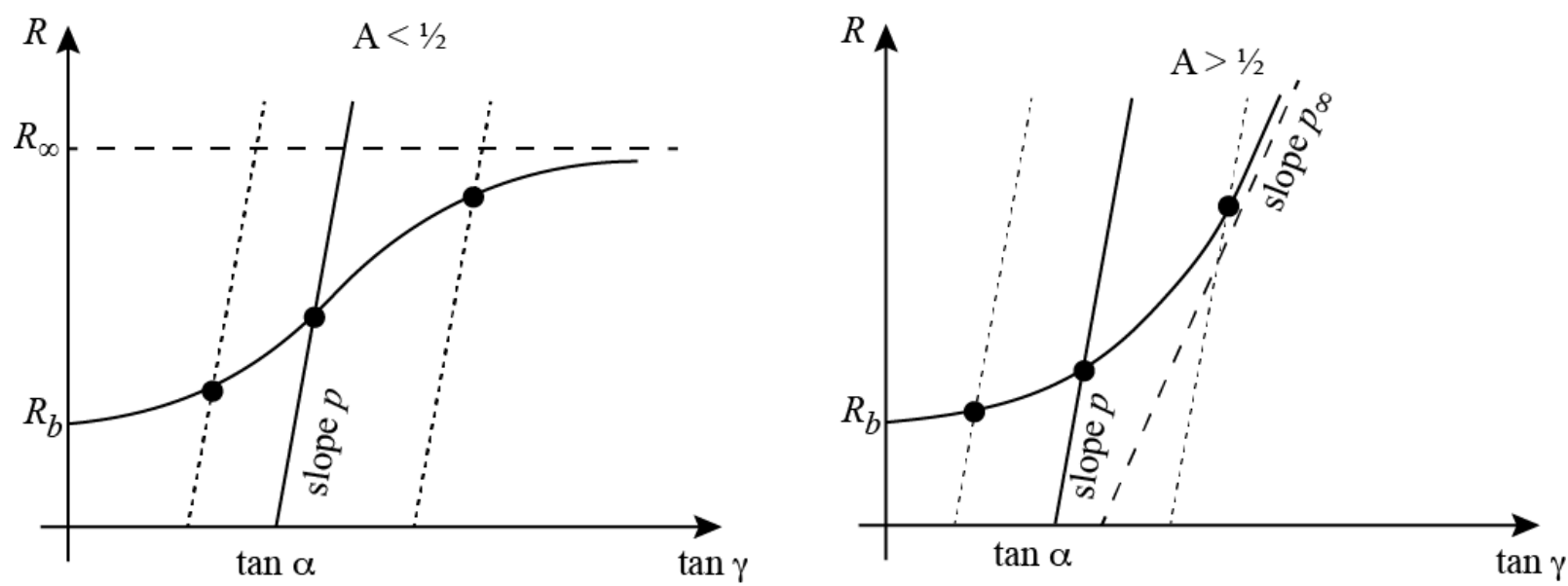

Figure 3. Qualitative illustration of the intersection of equations (11-12) when coefficient A is smaller than $1 / 2$ (left side) and when $A$ is greater than $1 / 2$ (right side). 
Consequently, two safety conditions with regard to fire eruptions can be expressed. The first one, i.e. $A<1 / 2$ is usually obtained when the fuel bed arrangement is well ordered (e.g. with vertically-oriented fuel particles at the laboratory scale) or when the number of gaps in the vegetal stratum is very important (at the field scale). This condition is rarely satisfied when facing an eruptive fire.

Using equations (5), (7) and the expression of $\mathrm{p}_{\infty}$ previously given, the second condition i.e. $A>1 / 2, p>p_{\infty}$ leads to the following ratio

$$
\left(\frac{p}{p_{\infty}}=\frac{\rho_{v}}{\tau_{0} B T_{a} T^{3}\left[\frac{Y}{4\left(C_{p} \Delta T+m \Delta h\right)}-\frac{1}{2 v \chi_{0} \Delta H}\right]}\right)>1
$$

where $T_{a}$ is the ambient temperature, $T$ the flame temperature, $\tau_{0}, B$ and $\chi_{0}$ are constant values. When the inequality (13) is satisfied, a fire eruption cannot occur. As soon as the ratio $p / p_{\infty}$ is smaller than 1 , a fire eruption becomes possible but not sure. In fact the lower the value of the ratio $p / p_{\infty}$ the more the fire eruption risk grows.

Several factors contribute to reduce the value of the ratio $p / p_{\infty}$ :

- Fuel bed properties

- A low density vegetation with small specific heat, where its density $\rho_{v}$ and the specific heat of vegetative fuel $C_{p}$ are small.

- A vegetative fuel with a light ligneous component. Indeed, the heat of combustion of the pyrolysis gases can be written as $\Delta H=(1-c) \Delta H_{T}-c \Delta H_{c}$, where $\Delta H_{T}$ is the heat of combustion of fuel $\left(\Delta H_{T} \approx 1.8 \times 10^{7} \mathrm{~J} \cdot \mathrm{kg}^{-1}\right), c$ the percentage of char and $\Delta H_{c}$ the heat of combustion of the char (Leroy et al. 2009). So, low char contents induce high values for $\Delta H$, and then the ratio given by equation (13) decreases. Furthermore, the cubic flame temperature $T^{3}$ strongly increases with $\Delta H$.

- A sufficient fuel load. Coefficient $v$ must be as great as possible $(v=1$ is the perfect situation for an eruption). As $v=\min (1, S / 4)$, the leaf area $S$ must be greater than 4. Moreover, as $S=\frac{s \sigma}{\rho_{v}}$, a low buoyancy (low density) and thin (important surface area to volume ratio) fuel satisfies this condition with a minimal fuel load of $\frac{4 \rho_{v}}{s}$.

- A dry vegetal stratum. Indeed, the moisture content $m$ is lower than the moisture content of a living vegetal stratum and the greater $m$, the smaller the ratio $p / p_{\infty}$.

- Environmental factors

- A high ambient temperature. $T_{a}$ plays a direct part in equation (13) but also through $\Delta T=T_{i}-T_{a}$ and through the flame temperature $T$ (Balbi et al. 2009). Note that a specific work (Chetehouna et al. 2009) shows that if summer temperatures are extreme $\left(\approx 40^{\circ} \mathrm{C}\right)$, some volatile organic compounds are probably emitted in a sufficient quantity to burn at a temperature lower than the usual temperature given for $T_{i}$ (around $550 \mathrm{~K}$ ). This issue deserves to be deepened and it would be useful to have a law for $\Delta T$ as a function of $T_{a}$.

- Assuming a homogeneous fuel bed (or a dead fuel bed), a low relative air humidity induces a low fuel moisture content (Ascoli and Bovio 2010).

- Factors related to fire dynamics

- A strong coefficient $Y$ (close to 1). This coefficient depends on the fire front width/flame length ratio. When the fire front width is large compared to the flame length, the coefficient $Y$ is close to 1 (e.g. in field scale configurations). 
To summarize, the required conditions to increase the fire eruption risk are:

- A low buoyancy vegetation, weakly ligneous, with a sufficient fuel load,

- Bad meteorological conditions (high ambient temperature, low relative humidity),

- A large fire front.

Dold and Zinoviev (2009) emphasized the impossibility to describe an eruption phenomenon with a steady-state model for the ROS. In our case, the steady state propagation model is only used to obtain the safety condition (13) because the danger condition represents its limit case. The expression of the ROS and consequently the fire behaviour during the eruption is obviously obtained using the unsteady version of the propagation model but this aspect is not studied in this work which only focuses on the eruption's occurring.

When the condition (13) is no longer satisfied, a fire eruption is probable but does not inevitably occur. The eruption's onset depends on the value of the slope angle. One can note that the safety condition (13) does not depend on the slope angle. If the slope angle is greater than a threshold value $\alpha_{c}$, fire will erupt. It is not possible to obtain an analytic expression of this threshold but only a numerical value which is found at any precision by solving the coupled model (11-12) with a fixed-point method.

One can also note that the model (11-12) can be used when a fire spreads downslope (i.e. for negative slope angle values) or on flat ground (as the eruptive fire occurred without wind and slope in the SaintGénis Des Fontaines' local site in the south of France in 2005). But in these cases, the value of the ratio $p / p_{\infty}$ has to be very small in order to obtain an eruption.

\section{Confrontation with laboratory experiments and a real accident}

Sets of data describing an eruptive behaviour are very rare in literature. So, testing the proposed approach is a difficult task. Two sets of laboratory scale experiments and a wildland fire that occurred on Kornati Island in 2007 were selected.

The first set of experiments was carried out by Viegas (2004b). Notice that the main goal of that set of experiments was only to observe fire propagations on slope.

The experimental bench (DV2 inclination table) had a useful $3 \mathrm{~m} \times 3 \mathrm{~m}$ area that could be inclined at any desired angle $\alpha$ between $0^{\circ}$ and $40^{\circ}$. The fuel bed used was made with dead pine needles (Pinus pinaster). The average fuel load was $0.8 \mathrm{~kg} \mathrm{~m}^{-2}$. The average moisture content was about $10-11 \%$.

No eruptions were observed, even with the steepest slopes $\left(30^{\circ}\right.$ to $\left.40^{\circ}\right)$. This is due to the intrinsic properties of the pinus pinaster needles and to a pointed head of the fire front, leading to a fast decrease of the fire front width, especially with steep slopes and then to a weak ratio fire front width/flame length $W / l$. The flame length is approximately $1 \mathrm{~m}$. The greatest width of the fire front $(3 \mathrm{~m}$ wide) leads to a value of the coefficient $Y$ equal to 0.75 . In this "worst" case, the value of coefficient $A$ is greater than $1 / 2(A=0.91)$ and the value of the ratio $p / p_{\infty}$ is much greater than $1\left(p / p_{\infty}=1.73\right)$. So the model does not predict any eruption even for a $40^{\circ}$ slope angle.

The second set of laboratory experiments was conducted by the CEIF (Centro de Estudos sobre Incêndios Florestais) laboratory of ADAI (Association for the Development of Industrial Aerodynamics) for Dold (2010) in which eruptions are observed for slope angles greater or equal than $30^{\circ}$.

The experiments consist in five trench fire experiments at $15^{\circ}, 20^{\circ}, 25^{\circ}, 30^{\circ}$ and $35^{\circ}$ slope angles. For the three lower slopes, the fire spreads in a usual way, but a very fast spread is observed for the two higher slopes. So eruption happens between $25^{\circ}$ and $30^{\circ}$.

The characteristics of the fuel bed (straw) that were used lead a lot more easily to a fire eruption than pinus pinaster's ones. Indeed, the great surface area to volume ratio $\left(s=10000 \mathrm{~m}^{-1}\right)$ or the small density of the vegetal particles $\left(\rho_{\mathrm{v}}=450 \mathrm{~kg} \cdot \mathrm{m}^{-3}\right)$ involve a smaller value of the ratio $\boldsymbol{p} / \boldsymbol{p}_{\infty}$ than the one obtained for pinus pinaster needles. 
Moreover, vertical walls are located on the sides of the inclination table. According to Catchpole et al. (1998), the role of these walls is to mimic a wider fire front by preventing indraft into the combustion zone and by reflecting some of the radiation.

The model provides a value of 1.21 for coefficient $A$ and a ratio $p / p_{\infty}$ smaller than $1\left(p / p_{\infty}=0.76\right)$. Then a fire eruption is possible. The value of the threshold slope angle is obtained in solving the equations (11-12). A $26^{\circ}$ slope angle is found which means that the fire eruption will occur only if the slope angle is greater than $26^{\circ}$. This threshold value is in accordance with the observed results.

The model was also confronted to a real fire that happened on the Kornati Islands, Croatia in 2007. This fire led to a dramatic fire-fighting accident causing the death of 12 fire fighters and severe burns for another one. The full description of this accident is detailed in Viegas et al. (2008) and Stipanicev et al. (2008).

The accident took place in the island of Kornat (the largest of 365 islands in Croatia's Kornati National Park). The fire started $6.6 \mathrm{~km}$ from the accident, which occurred in a small canyon (500 $\mathrm{m}$ long). The fuel load was low and made of sparse vegetation, mostly grass of approximately $30 \mathrm{~cm}$ with a few small isolated trees and bushes. The fuel load ranged from $0.561 \mathrm{~kg} \cdot \mathrm{m}^{-2}$ to $0.837 \mathrm{~kg} \cdot \mathrm{m}^{-2}$ and the average vegetation low heating value was estimated to be $1.8 \times 10^{7} \mathrm{~J}_{\mathrm{kg}} \mathrm{kg}^{-1}$. The moisture content of the fine fuel mass was equal to $10-12 \%$. The canyon's main axis was directed to the north with a $15 \%$ (about $9^{\circ}$ ) average slope. A camera was found at the location of the accident. A large fire front (of about $50 \mathrm{~m}$ ) was clearly seen on a photo from this camera (Stipanicev and Viegas 2009), with small flame lengths (below $1 \mathrm{~m})$. So the parameter $\mathrm{Y}$ is close to 1 in this case $(Y=0.98)$.

On the Kornat Island, the fire was pushed by a S-E wind (about $40 \mathrm{~km} / \mathrm{h}$ at $10 \mathrm{~m}$ height). According to the only fire-fighter who survived the accident of Kornati, the important fact was the very strong wind. In the canyon, the wind changed its direction to become parallel to the main canyon axis and the fire front was spreading at very high speed, maybe 6 or $7 \mathrm{~m} \cdot \mathrm{s}^{-1}$. His words are confirmed by the melted particles of a fire-fighter belt buckle found on a stone behind the place where his body was laying, which prove that the wind generated by the fire was very strong and coming from the south. The fireinduced wind, which grew to be stronger than the S-E wind and changed its direction, had clearly a key role in the occurrence of the eruption. Note that the few trees here have not been burnt. That means that flames were very slanted (in agreement with the flame attachment assumption).

The simulation results with $\mathrm{Y}=0.98$ and an average fuel load $(0.7 \mathrm{~kg} \cdot \mathrm{m}-2)$ give the initiation of eruption for a slope angle $\alpha=8^{\circ}$, which is in accordance with the average slope of the canyon. Indeed, the value of coefficient $A$ is equal to 1.24 and the ratio $p / p_{\infty}$ is smaller than $1\left(p / p_{\infty}=0.86\right)$.

\section{Conclusion}

If a few works about modeling of a fire ROS during an eruption can be found in the literature (e.g. Viegas 2005, Dold et al. 2011), to our knowledge none of them are able to predict the eruption's onset. This work focuses on a physical safety condition which means that a fire cannot erupt if this condition is satisfied. Otherwise, an eruption is either possible or certain. The physical model proposed in this work consists mainly of one propagation equation and one equation providing the induced wind created by the fire.

The explanation of the eruption phenomenon is the following: if the slope angle is sufficient enough, the combustion of the pyrolysis gases creates an indraft proportional to the flow of these gases that is related to the fire front depth and then to the ROS. So, there is a coupling between ROS and induced wind that created a feedback effect leading to unsteady growing propagation. Note that this interpretation was given by Viegas (2005).

Usually this unsteady phase converges to a steady phase, but under some conditions, this unsteady phase grows exponentially and a fire eruption occurs.

The specific conditions leading to certain eruption $(\mathrm{p}<\mathrm{p} \infty$ and $\alpha>\alpha \mathrm{c})$ are obtained with:

- Dry summer conditions (weak humidity, great ambient temperature), 
- Low density vegetation, slightly ligneous (e.g. grass),

- View factor of the fire front close to 1 ,

- Slope angle important enough.

The two last conditions are usually contradictory: it is well known that if the slope is steep, the fire front presents a 'pointed' effect with a narrow fire head. Then, the coefficient $Y$ is small and the condition $p<p_{\infty}$ is satisfied with difficulty. This pointed effect is due to the induced wind, which reduces the view factor on the edges of the fire front. The ROS at the edges of the fire front is then close to the backward ROS.

The right situation for a fire eruption is obtained when this induced wind downslope does not exist. This can happen when:

- The inclined plane is lined with 'walls', i.e. a trench effect or corridor topography. The nature of this topographic concavity may be geological (rocks) or constituted by a vegetation stratum (e.g. hillside lined with forests). So, in order to obtain a Y coefficient close to 1, the fire front width must be much greater than the flame length. The eruption can only develop in long corridors that let the positive feedback happen before the fire reaches any topographic limits. The trench effect defined by Sharples et al. (2010), especially the King Cross underground disaster, is part of this first case.

- Vegetation made of two different layers - a lower stratum and a higher stratum, such as shrubs and trees - is covering a hill. If the lower layer is burning and the induced wind is strong enough, the flames will not reach the canopy and the fire will remain a surface fire. The induced wind coming upslope can enter the flame front from the burned area but vegetation slows down the induced wind coming downslope and the pointed head effect will not appear. So, the fire front width may be much greater than the flame length and then, $\mathrm{Y} \propto 1$. For example, the Canberra fire in 2003, or the black Saturday fires in 2009, may be part of this second case.

In these two cases (corridor and bi-strata), the Y coefficient is close to 1 . If the moisture content is of the order of $10 \%$, a fuel bed with averaged properties (surface area to volume ratio, density, specific heat, height, fuel load) will give the following results: $\mathrm{p}_{\infty}=2 \mathrm{p}, \alpha_{\mathrm{c}}=15^{\circ}, \mathrm{R}=6.4 \mathrm{~m} \cdot \mathrm{s}^{-1}$ after $60 \mathrm{~s}$ and $\mathrm{L}=128 \mathrm{~m}$. This example corresponds to the blow up phenomenon described by the fire-fighters.

Apart from these two cases, the decrease in coefficient $Y$ will not provide a fire eruption faced to topographies as inclined plateau or hill with convex shape.

\section{References}

F.A. Albini (1985) A model for fire spread in wildland fuels by radiation, Combustion Science and Technology, 42, 229-258.

H.E. Anderson (1969) Heat transfer and fire spread, United States Department of Agriculture Forest Service, Research Paper INT-69.

P.L. Andrews (1986) BEHAVE: fire behavior prediction and fuel modelling system - BURN Subsystem, part 1, General Technical Report INT-194. Ogden, UT: U.S. Department of Agriculture, Forest Service, Intermountain Research Station, 130p.

D. Ascoli, G. Bovio (2010) Appraising fuel and fire behaviour for prescribed burning application in heathlands of Northwest Italy, D.X. Viegas (Ed.) VI International Conference on Forest Fire Research proceedings, Coimbra.

J.H. Balbi, J.L. Rossi, T. Marcelli, P.A. Santoni (2007), A 3D physical real-time model of surface fires across fuel beds, Combustion Science and Technology, 179:12, pp. 2511-2537.

J.H. Balbi, F. Morandini, X. Silvani, J.B. Filippi, F. Rinieri (2009), A physical model for wildland fires, Combustion and Flame, 156, 2217-2230.

J.H. Balbi, J.L. Rossi, T. Marcelli, F.J. Chatelon (2010), Physical modeling of surface fire under nonparallel wind and slope conditions, Combustion Science and Technology, 182, pp. 922-939. 
B.W. Butler, R.A. Bartlette, L.S. Bradshaw, J.D. Cohen, P.L.Andrews, T. Putnam, R.J. Mangan (1998), Fire behavior associated with the 1994 South Canyon Fire on Storm King Mountain, Colorado, USDA, Forest Service, RMRS-RP-9, Ogden, UT, 82 p.

W.R. Catchpole, E.A. Catchpole, B.W. Butler, R.C. Rothermel, G.A. Morris, D.J. Latham (1998) Rate of spread of free-burning fires in woody fuels in a wind tunnel, Combustion Science and Technology, 131, 1-37.

F.J. Chatelon, J.H. Balbi, B. Moretti, T. Marcelli, J.L. Rossi (2010), Fast and slow regimes of fire propagation, D.X. Viegas (Ed.) VIe ICFFR proceedings, Coimbra, 2010.

N.P. Cheney, J.S. Gould (1995) Fire Growth in Grassland Fuels, International Journal of Wildland Fire, 5(4), 237-247.

K. Chetehouna, T. Barboni, I. Zarguili, E. Leoni, A. Simeoni, A.C. Fernandez-Pello (2009) Investigation on the emission of Volatile Organic Compounds from heated vegetation and their potential to cause an eruptive forest fire, Combustion Science and Technology, 181:10 (2009), pp. 1273-1288.

J.W. Dold, A. Zinoviev (2009), Fire eruption through intensity and spread rate interaction mediated by flow attachment, Combustion Theory and Modelling, 13, pp. 763-793.

J.W. Dold (2010), Flow attachment in eruptive fire growth, D.X. Viegas (Ed.) VI International Conference on Forest Fire Research proceedings, Coimbra, 2010.

J.W. Dold, A. Zinoviev, E. Leslie, (2011) Intensity accumulation in unsteady firelines: A simple model for vegetation engagement, Fire Safety Journal, 46, pp. 63-69.

P.A. Fernandes (2001) Fire spread prediction in shrub fuels in Portugal, Forest Ecology Management, $144,67-74$.

M. Guijarro, C. Hernando, J.A. De Los Santos, C. Diez (1997) Forest Fire behaviour on the wind tunnel, Hefaistos Project Report, ENV4-CT96-0299.

E. Koo, P. Pagni, J. Woycheese, S. Stephens, D. Weise, J. Huff (2005) A Simple Physical Model for Forest Fire Spread Rate, In 'Fire Safety Science-Proceedings of the eighth international symposium', 851-862.

V. Leroy, D. Cancellieri, E. Leoni, (2009) Relation between forest fuels composition and energy emitted during their thermal degradation, Journal of thermal analysis and calorimetry, 96(1), pp. 293-300.

A.G. McArthur (1969), The behavior of mass fires in felled eucalypt forest originating from a simultaneous grid or line ignition system, in Mass Fire Symposium, Defense Standards Laboratory, Canberra, Australia, Paper A1.

T. Marcelli, J.H. Balbi, B. Moretti, J.L. Rossi, F.J. Chatelon (2011) Flame height model of a spreading surface fire, In 'Proceedings of the seventh Mediterranean Combustion Symposium (The Combustion Institute)', Chia Laguna, Cagliari, Italy, september 11-15, pp 12.

J.M.C. Mendes-Lopes, J.M.P. Ventura, J.M.P. Amaral (2003) Flame characteristics, temperature-time curves, and rate of spread in fires propagating in a bed of Pinus pinaster needles, International Journal of Wildland Fire, 12, 67-84.

P.J. Pagni, G. Peterson (1973) Flame spread through porous fuels, In 'proceedings of 14th Symposium (International) on Combustion', 1099-1107. (The Combustion Institute)

J.J. Sharples, A.M. Gill, J.W. Dold (2010) The trench effect and eruptive wildfires: lessons from the King's Cross underground disaster, Proceedings AFAC 2010.

D. Stipanicev, Z. Spanjol, M. Vucetic, V. Vucetic, R. Rosavec, Lj.Bodrozic (2008) The Kornati fire accident facts and figures - configuration, vegetation and meteorology, Witpress (Ed.) Modelling, Monitoring and Management of forest fires, Vol. I, pp 387-396.

D. Stipanicev, D.X. Viegas (2009), The accident of Kornati (Croatia) 2007, Recent Forest Fire Related Accidents in Europe, JRC Scientific and Technical Reports, 75 pp., 26-53, doi:10.2788/50781.

H.P. Telisin (1974) Flame radiation as a mechanism of fire spread in forests, In 'Heat Transfer in Flames', Afgan N.H. and Beer J.M. (Eds), John Wiley and Sons, New York, p. 441. 
C.E. Van Wagner (1967) Calculations on forest fire spread by flame radiation. Special paper for the sixth World Forestry Conference, 1-14.

D.X. Viegas, M.G. Cruz, L.M. Ribeiro, A.J. Silva, A. Ollero, B. Arrue, R. Dios, F. Gomez-Rodriguez, L. Merino, A.I. Miranda, P. Santos (2002) Gestosa fire spread experiments. In 'Proceedings of the IV ICFFR, Luso, Portugal, 18-23 November 2002', (Ed. DX Viegas)(Millpress Science Publishers: Rotterdam, The Netherlands).

D.X. Viegas (2004a), Slope and wind effects on fire propagation, International Journal of Wildland Fire, 13, pp. 143-156.

D.X. Viegas (2004b), On the existence of a steady state regime for slope and wind driven fires, International Journal of Wildland Fire, 13, pp. 101-117.

D.X. Viegas (2004c), Cercados pelo Fogo (in Portuguese), Minerva Editora (Eds), 274 pp.

D.X. Viegas (2005), A mathematical model for forest fires blowup, Combustion Science and Technology, 177:1, pp. 27-51.

D.X. Viegas, L.P. Pita (2004), Fire spread in canyons, International Journal of Wildland Fire, 13, pp. 253-274.

D.X. Viegas, D. Stipanicev, L. Ribeiro, L.P. Pita, C. Rossa (2008) The Kornati fire accident - eruptive fire in relatively low fuel load herbaceous fuel conditions, Witpress (Ed.) Modelling, Monitoring and Management of forest fires, Vol. I, pp. 365-375.

D.X. Viegas, A. Simeoni (2011) Eruptive behaviour of forest fires, Fire Technology, 47(2), pp. 303320, doi: 10.1007/s10694-010-0193-6. 